\title{
Expansão rápida da maxila
}

\section{Leopoldino Capelozza Filho*}

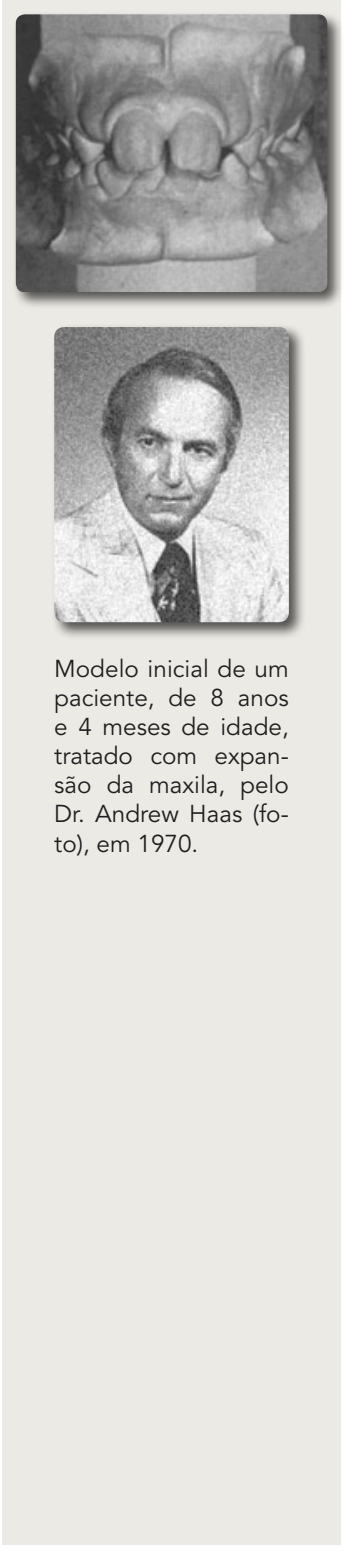

Expansão rápida da maxila: sinônimo de Haas. Porque, para a Ortodontia, é inquestionável que foi ele, o professor Andrew J. Haas, o introdutor desse procedimento de grande valia. Para os profissionais que introduziram e estabeleceram o serviço de Ortodontia no Hospital de Reabilitação de Bauru (Centrinho) e, acredito, para muitos ou todos que de alguma maneira estudaram ou conviveram com essa filosofia, essa correlação é ainda mais forte. Tratando pacientes com fissura, onde a atresia maxilar era regra, a descoberta da possibilidade de expandir a maxila teve um valor inestimável. Impossível não ter extrema admiração pelo seu idealizador. Tivemos a oportunidade de mostrar isso ao professor Haas quando ele veio a Bauru, em 2001, muito mais do que para participar de um congresso científico, para receber nossas homenagens e nosso carinho.

O tempo, os estudos - que são milhares - e principalmente as evidências clínicas confirmaram a exatidão da previsão feita por meio do título de um de seus artigos, predestinando a expansão rápida da maxila como o início da Ortopedia dentofacial**. Infelizmente, não fomos muito além nesse vaticínio, considerando que, provavelmente, nossas ações ortopédicas não conseguem extrapolar os efeitos sobre a maxila.

Mas, nesse particular, temos nos tornado mais hábeis. Conforme será demonstrado nessa edição da revista Dental Press, especialmente dedicada ao assunto expansão rápida da maxila, esse recurso mecânico tem sido utilizado com múltiplos objetivos. A entrevista com o Prof. Liou, que apresenta o "melhor texto sobre seu protocolo de expansões e contrações sucessivas", vai confirmar que, ao contrário de algumas "evidências científicas", expandir a maxila é condição imperativa para o sucesso na tração maxilar em pacientes com padrão III de crescimento facial. Os outros artigos, assinados por profissionais envolvidos com esse assunto, vão continuar fornecendo bases para que o uso da expansão rápida da maxila seja adequado, como auxiliar no tratamento de diferentes más oclusões e em pacientes de idades variadas. Considerando suas limitações e efeitos colaterais, protocolos cada vez mais bem elaborados serão utilizados, permitindo obter o efeito maior da expansão rápida da maxila: expandir os limites da prática da Ortodontia.

\footnotetext{
* Professor doutor da Universidade de São Paulo, professor visitante da Universidade Estadual Paulista Júlio de Mesquita Filho, ortodontista do Hospital de Reabilitação de Anomalias Craniofaciais da Universidade de São Paulo, coordenador dos cursos de Especialização em Ortodontia (Profis) e de Pós-Graduação em Fissuras Orofaciais - Mestrado (HRAC-USP).

** HAAS, A. J. Palatal expansion: Just the beginning of dentofacial orthopedics. Am. J. Orthod., St. Louis, v. 57, no. 3, p. $219-255$, Mar. 1970.
} 